\title{
CONTEXTO GEOAMBIENTAL EM SÍTIO URBANO NA SUB-BACIA HIDROGRÁFICA DO RIO BANABUIÚ - CE
}

\section{Environmental context in urban sites in the Banabuiú River water basin - CE}

\author{
Luis Ricardo Fernandes da Costa $^{1}$ https://orcid.org/0000-0001-8593-861X \\ Vládia Pinto Vidal de Oliveira ${ }^{2}$ https://orcid.org/0000-0001-7756-9009 \\ Jader de Oliveira Santos ${ }^{3}$ https://orcid.org/0000-0003-2977-7086
}

\footnotetext{
${ }^{1}$ Doutor em Geografia - Universidade Estadual de Montes Claros - UNIMONTES. E-mail: 1ricardocosta@ yahoo.com.br

${ }^{2}$ Doutora em Engenharia Agronônima - Universidade Federal do Ceará - UFC. E-mail: vladia.pinto@ gmail.com

${ }^{3}$ Doutor em Geografia - Universidade Federal do Ceará - UFC. E-mail: jadersantos@gmail.com
}

\begin{abstract}
Resumo
O trabalho aborda a questão geoambiental na bacia hidrográfica do rio Banabuiú e tece características dos sítios urbanos de Pedra Branca e Quixeramobim, com o objetivo de levantar questões acerca da relação da bacia com as cidades. A metodologia do trabalho consistiu-se em quatro etapas: 1) Revisão bibliográfica e documental sobre a área, assim como o material cartográfico disponível; 2) Elaboração de mapas básicos das áreas; 3) Expedições de Campo para análise preliminar, registro fotográfico e adequações cartográficas; 4) Tabulação e interpretação dos dados de campo; 5) Expedições de Campo para comprovação dos dados e adequações do produto final. A abordagem temática de forma interdisciplinar tem o objetivo de visualizar problemas complexos que estão ligados à gestão e planejamento ambiental, ainda mais quando se trata de ambientes urbanos, como em pequenas e médias cidades com potencial crescimento de sua malha urbana.
\end{abstract}

Palavras-chave: Análise ambiental. Bacia do rio Banabuiú. Sítio urbano.

\begin{abstract}
The work deals with environmental issues in the basin of river Banabuiú and weaves characteristics of urban sites of Pedra Branca and Quixeramobim, in order to raise questions about the relationship of the basin with the cities. The methodology of work consisted in four steps: 1) bibliographic and documentary review on the area, as well as the available cartographic material; 2) Development of basic maps of areas; 3) Holiday Expeditions to preliminary analysis, cartographic photographic record and adjustments; 4) Tabulation and interpretation of field data; 5) Holiday Expeditions for verification of the data and adjustments of the final product. The thematic approach in an interdisciplinary way aims to visualize complex problems that are linked to environmental management and planning, especially when it comes to urban environments, such as in small and medium cities with the potential growth of its urban fabric.
\end{abstract}

Keywords: environmental analysis. River basin Banabuiú. Urban site. 


\section{Introdução}

Os estudos ambientais têm cada vez mais a necessidade de comunicação com outros ramos da ciência. No âmbito da Geografia, a análise ambiental tem se constituído base precípua para a aplicação de estudos em Geografia Física, logo por se mostrar como caminho metodológico da visão holística.

A integração, vista dessa maneira, acabou por ficar restrita ao campo das disciplinas específicas (geologia, geomorfologia, hidrologia, solos e cobertura vegetal), por vezes ignorando importantes aspectos da Geografia socioespacial.

Essa defasagem e mesmo dualidade entre Geografia física x Geografia humana, acabou por desvalorizar o conhecimento geográfico, e mesmo seu processo de reconhecimento perante a comunidade científica e a sociedade civil.

A valorização, no âmbito da análise per si dos ramos da Geografia, foram de todo fundamentais para a compreensão da realidade em diversas escalas de análise, mas incompatíveis com o esforço de se realizar estudos holísticos e de cunho efetivo para a sociedade.

Desse modo, o sítio urbano acaba por se uma opção de estudo interdisciplinar, que exige apreensão de aspectos variados da estruturação geoambiental e de uso e ocupação. Dessa forma o trabalho, ainda em desenvolvimento, aborda a questão geoambiental da bacia hidrográfica do rio Banabuiú e tece características dos sítios urbanos de Pedra Branca e Quixeramobim, com o objetivo de levantar questões acerca da relação da bacia com as cidades.

A metodologia do trabalho consistiu em cinco etapas: 1) Revisão bibliográfica e documental sobre a área, assim como o material cartográfico disponível; 2) Elaboração de mapas básicos das áreas; 3) Expedições de Campo para análise preliminar, registro fotográfico e adequações cartográficas; 4) Tabulação e interpretação dos dados; 5) Expedições de Campo para comprovação dos dados e adequações do produto final.

\section{Desenvolvimento}

\section{Sistemas ambientais e a bacia hidrográfica na análise ambiental}

Os estudos integrados têm desempenhado papel importante dentro das ciências da natureza, fato esse que se justifica pelos inúmeros trabalhos que buscam a visão sistêmica do meio ambiente. A Geografia nesse sentido tem um papel importante e unificador nesse processo. 
A relação sociedade-natureza, bem como todo o saber e conhecimento sobre o mundo e as coisas, há muito tempo tem estado condicionado pelo contexto geográfico e ao mesmo tempo, associado ao ecológico e cultural em que produz e reproduz as variações da formação social (ROCHA, 2011).

Para tanto, autores como Bertalanffy (1973), Bertrand (1971), Tricart (1962, 1977, 1981), Oliveira (1990), Ross (1994), Christofoletti (1999), Souza (2000), Souza e Oliveira (2011), Santos e Ross (2012), Santos e Souza (2014) estabelecem as bases teóricas e metodológicas da pesquisa, a ressaltar que o esforço para o manuseio dos elementos por qual o trabalho percorre objetiva a análise sistêmica, pautada nos estudos da Geografia física aplicada.

Christofoletti (1999) destaca a importância dos estudos sistêmicos, mas não se esquecendo do valor das suas partes componentes. Para tanto, o autor frisa que a abordagem holística sistêmica é necessária para compreender como as entidades ambientais físicas, por exemplo, expressando-se em organizações espaciais, se estruturam e funcionam como diferentes unidades complexas em si mesmas (CHRISTOFOLETTI, 1999).

Nesse sentido, Souza e Oliveira (2011) discutem a importância da interdisciplinaridade nos estudos atuais. Para tanto, os autores enfatizam a necessidade de percepção do conjunto tido como requisito fundamental da interdisciplinaridade, que requer a consideração dos mecanismos que integram harmonicamente o ambiente, considerando a sua complexidade e heterogeneidade.

Os sistemas ambientais representam entidades organizadas na superfície terrestre, onde sua espacialidade se torna uma característica fundamental e necessária. (CHRISTOFOLETTI, 1999).

A análise geoambiental em tal contexto procura fundamentar-se como um instrumento para a análise sistêmica. A identificação e hierarquização dos componentes são de fundamental importância para o sucesso na análise dos sistemas ambientais, assim como aponta os autores:

Os sistemas ambientais são identificados e hierarquizados conforme a inter-relação dos seus componentes geoambientais, suas dimensões e características de origem e evolução. Considerando a diversidade interna dos sistemas, são delimitadas as unidades elementares contidas em um mesmo sistema de relações que configura, espacialmente, os subsistemas. Sob esse aspecto, a concepção de paisagem assume significado para a delimitação das subunidades, em decorrência da exposição de padrões fisionômicos uniformes ou de relativa homogeneidade (SANTOS e SOUZA, 2014, p. 222 e 223). 
Nesse sentido, os sistemas ambientais podem ser aplicados em diversas unidades de planejamento, seja em áreas de bacias hidrográficas até núcleos urbanos de pequenas e médias cidades. O importante na análise é procurar satisfazer os critérios de integração dos elementos biofísicos em cada situação.

Figura 1: Síntese metodológica para compreensão dos sistemas ambientais

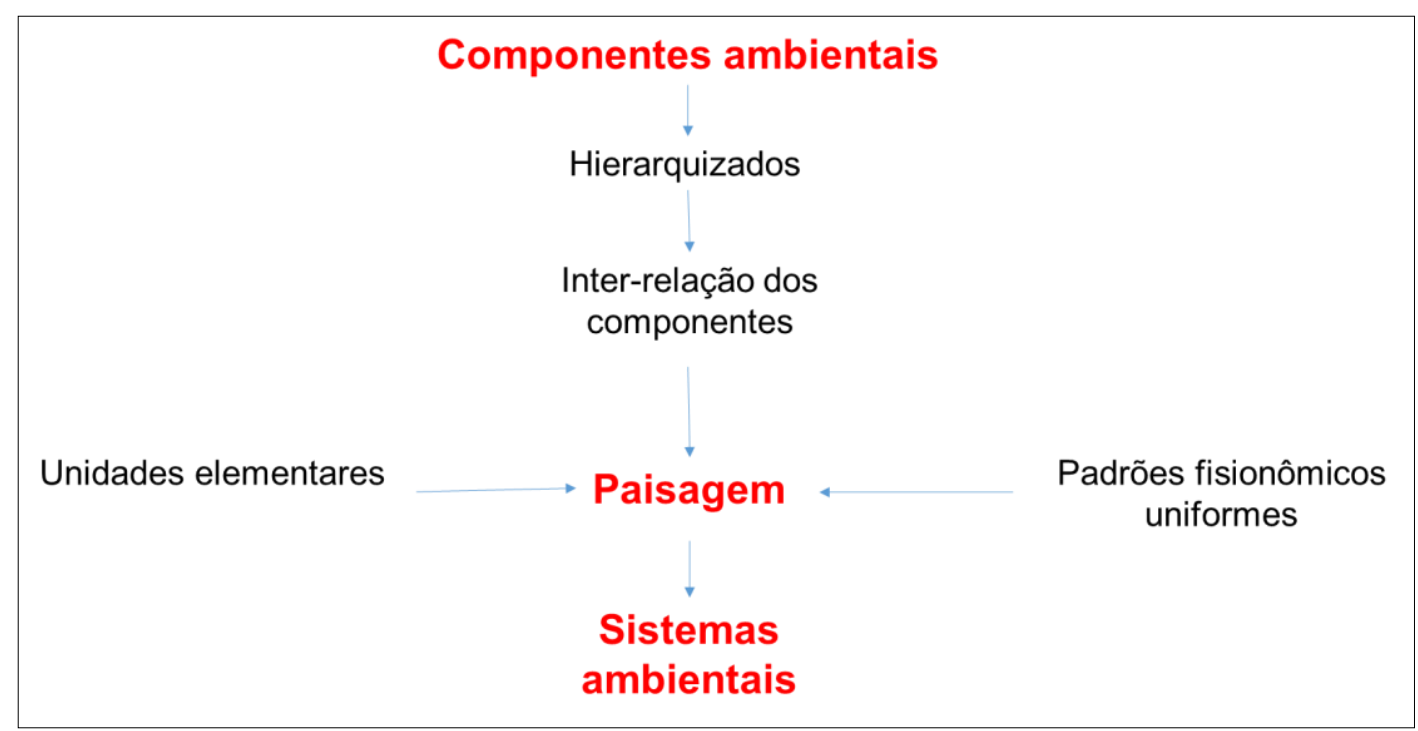

Fonte: Costa, L. R. F (2016)

Para a compreensão do sítio urbano em consonância com a bacia hidrográfica, é válido ressaltar o esforço na abordagem holística, na qual será evidenciada com mais clareza com o desenvolvimento do trabalho.

A bacia hidrográfica pode ser concebida como célula básica de análise ambiental, que permite conhecer e avaliar seus diversos componentes e os processos e interações que nela ocorrem. A visão sistêmica e integrada do ambiente está implícita na adoção desta unidade fundamental (BOTELHO e SILVA, 2004).

De acordo com Guerra e Guerra (1997), a bacia hidrográfica pode ser considerada como um conjunto de terras drenadas por um rio principal e seus afluentes. No entanto, podemos encontrar outras definições para a compreensão dessa célula de estudo e sua importância para os estudos integrados.

Os problemas enfrentados no planejamento dos recursos hídricos têm incitado a utilização cada vez mais de abordagens integradas, e, como já foi dito anteriormente, a bacia de drenagem é uma dessas possibilidades. 
Segundo Pires e Santos (1995), abordagens de planejamento e gerenciamento que utilizam a bacia hidrográfica como unidade de trabalho têm evoluído em aspectos da gestão e do planejamento. Os autores destacam ainda que

\begin{abstract}
As características biogeofísicas dessas bacias apresentam sistemas ecológicos e hidrológicos relativamente coesos. No início, o processo de gerenciamento e planejamento de bacias hidrográficas visa basicamente à solução de problemas relacionados à água, prioridade para o controle de inundações, para a irrigação, navegação ou para o abastecimento público e industrial (PIRES e SANTOS, 1995, p.41).
\end{abstract}

Ainda segundo os autores, essa abordagem mais complexa busca solucionar conflitos entre os usuários e dimensionar a qualidade e quantidade de recursos que cabe a cada um, assim como suas responsabilidades sobre tais recursos (PIRES e SANTOS, 1995).

\title{
Sítio urbano como categoria analítica em Geografia
}

A problemática urbana vem crescendo nos últimos anos, muito em consonância com o planejamento deficiente e a gestão precária e sem participação dos variados envolvidos em determinado setor da sociedade.

O estudo do sítio urbano enquanto objeto de análise é importante, tendo em vista os

variados elementos que proporcionam integração dos elementos físicos, a destacar a geomorfologia como atributo âncora da análise integrada (TRICART, 1962, 1977; AB'SABER, 1975, 2007; SOUZA, 1981; CASTILHO, 2011; SANTOS e ROSS, 2012).

A compreensão dos processos morfodinâmicos se constitui como elemento essencial na visualização de problemas que venham a se desenvolver, seja a médio ou a longo prazo. Definir os elementos dessa natureza é algo imprescindível para o estabelecimento da geografia física aplicada.

O estabelecimento do sítio urbano como categoria analítica, pressupõe um arcabouço teórico para a concepção desta unidade de cunho integrativa em unidade morfodinâmica. Os sistemas morfodinâmicos, dessa maneira, são ponto de discussão para a forma de intervenção no meio físico. Estabelecer as diversas formas de interação ambiental e a posterior representação cartográfica é elemento basilar nos estudos geográficos aplicados.

\section{A bacia hidrográfica do rio Banabuiú}

A bacia do Banabuiú constitui-se como uma sub-bacia do rio Jaguaribe, juntamente com as sub-bacias do Alto, Médio e Baixo Jaguaribe e sub-bacia do Salgado. A área da bacia 
compreende, essencialmente, os municípios localizados nos sertões centrais, limitando-se com quase todas as bacias do estado, com exceção das bacias do Coreaú, do litoral e a sub-bacia do salgado (CEARÁ, 2009).

O Banabuiú é o rio principal, cuja sub-bacia drena uma área aproximada de 19.810 $\mathrm{km}^{2}$, desenvolve-se no sentido oeste-leste e percorre um curso total de $314 \mathrm{~km}$, até desaguar no rio Jaguaribe nas proximidades com a cidade de Limoeiro do Norte. Sua área equivale a 13\% do território cearense (CEARÁ, 2009).

Figura 2: Localização da bacia do Rio Banabuiú e os sítios urbanos de Pedra Branca e Quixeramobim.

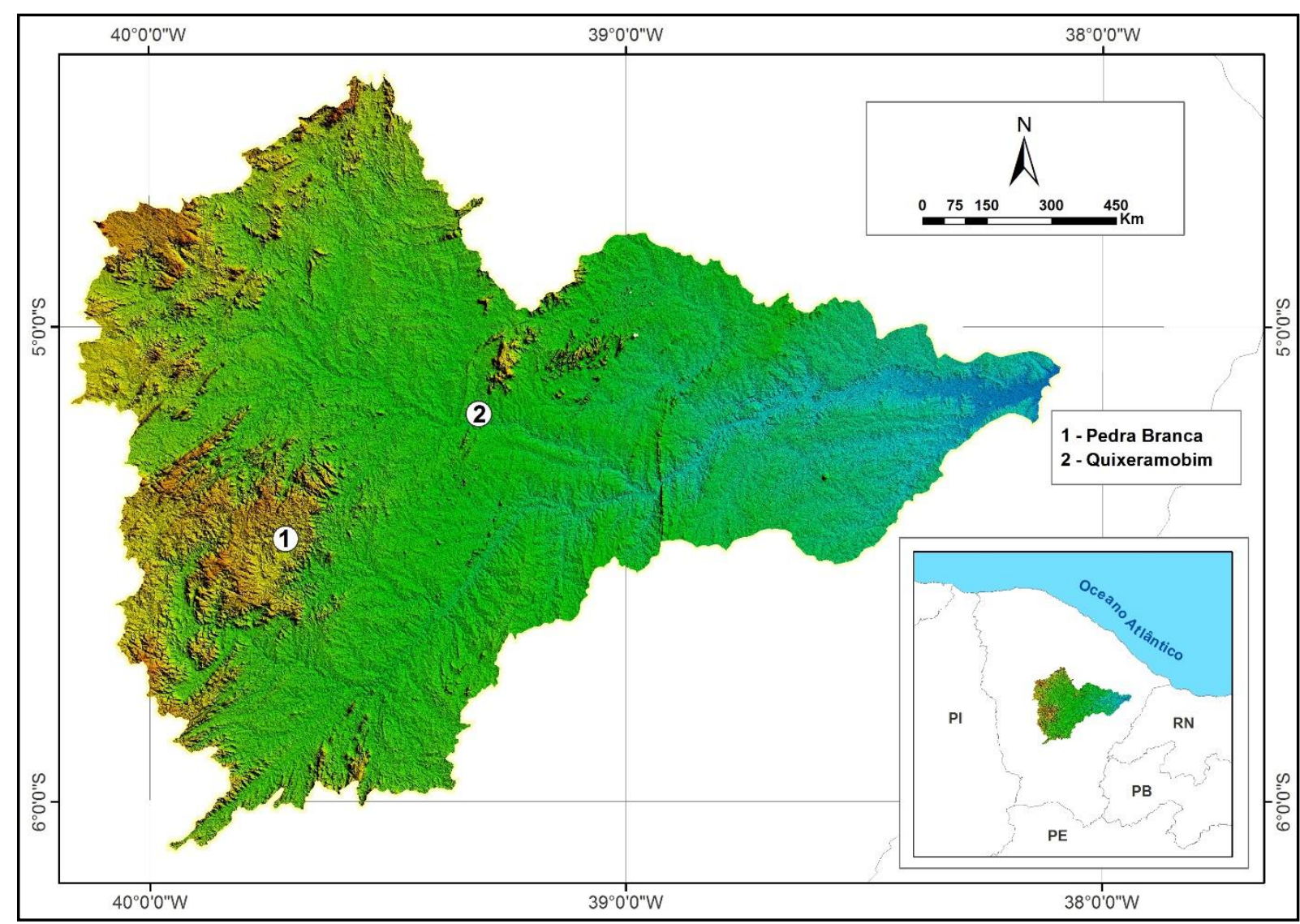

Fonte: Costa, L. R. F (2016).

Pela grande extensão, a bacia hidrográfica do rio Banabuiú possui importantes afluentes que irão compor um conjunto de características geoambientais na área dos sertões centrais. Seus afluentes a margem esquerda são os rios Patu, Quixeramobim e Sitiá, e a margem direita apenas o Riacho Livramento (CEARÁ, 2009).

A sub-bacia hidrográfica do Banabuiú apresenta um padrão geológico homogêneo, observando-se um predomínio de rochas do embasamento cristalino $(96,53 \%)$, representadas 
por gnaisses e migmatitos diversos, associados a rochas plutônicas e metaplutônicas de composição predominantemente granítica (CEARÁ, 2009).

Sobre esse substrato, repousam os sedimentos $(3,47 \%)$ Paleógenos e Neógenos do Grupo Barreiras, coberturas Cenozoicas, que afloram sob a forma de manchas esparsas, ao longo da região, e coberturas aluviais, de idade Quaternária, encontradas ao longo das calhas fluviais (CEARÁ, 2009).

As condições geomorfológicas do vale do Banabuiú (Mapa 3), são expressas essencialmente pela condição de aridez, expressa na conjuntura de um vasto Pediplano (SOUZA, 1988), condicionado através dos pedimentos que se inclinam deste a base dos maciços residuais.

São áreas aplainadas que na área de abrangência da bacia é dividida em dois níveis distintos. O primeiro nível, com altimetrias que variam entre 100 a 250 metros, e o segundo nível, entre 250 a 400 metros, alcançando a base dos maciços residuais.

O clima regional, predominantemente semiárido, apresenta irregularidades pluviométricas temporo-espaciais. O regime pluviométrico é do tipo tropical com um curto período chuvoso e um prolongado período de estiagem.

A irregularidade pluviométrica atinge máximos de estiagem, ocorrendo secas calamitosas e também chuvas excepcionais que provocam cheias, primordialmente nas áreas adjacentes aos grandes vales fluviais, como por exemplo, o caso do rio Jaguaribe (SOUZA et al., 2002).

Os solos da área são caracterizados pela ocorrência da associação de Planossolos Solódicos, Neossolos Flúvicos, Neossolos Litólicos, Luvissolos, Argissolos, Chernossolos, além de outros. A vegetação é caracterizada pela ocorrência de vários estratos, variando desde a caatinga arbustiva a caatinga arbórea.

\section{Os sítios de Pedra Branca e Quixeramobim}

Nesse sentido, é importante analisar a relação da bacia hidrográfica e todo o seu contexto ambiental e os aglomerados urbanos, de tal modo que a compreensão dos aspectos físico-naturais do sítio urbano esteja relacionado além do local, com o regional, ou seja, na relação com a situação geográfica.

O sítio urbano de Pedra Branca é caracterizado pela presença de unidades relacionadas aos maciços residuais, ou seja, grandes elevações em meio às áreas aplainadas das depressões sertanejas. A singularidade de estar localizada em altitudes que variam de 500 a 515 metros 
não oferece condições favoráveis de aporte de umidade, assim como as serras de Baturité e Meruoca, próximas do litoral.

De tal modo, que Pedra Branca é típico sítio urbano encravado em serra seca, ou seja, com condições que a aproximam da depressão sertaneja. A cidade (figura 3), atualmente é circundada pela presença de amplas colinas rasas, entalhadas pela rede de drenagem. A morfologia de colinas por vezes é alterada pelo aparecimento de cristas residuais e inselbergs, que dominam a paisagem a medida que a depressão sertaneja se estabelece.

O sítio urbano de Quixeramobim é típico de áreas de planície fluvial (figura 4). Importante destacar a relação dessa configuração com o processo histórico de ocupação do Estado do Ceará, onde a maioria das cidades se desenvolveu em áreas de planícies e antigos terraços fluviais, em decorrência das melhores condições em termos de recursos hídricos para a agricultura e subsistência local.

Além de constituir-se como cidade que desenvolveu-se em áreas das aluviões, as áreas subsequentes da sede exibem amplo Pediplano com considerável dissecação, com presença de colinas, inselbergs e planícies alveolares. Cabe destacar estas ultimas, por abrigarem condições mais favoráveis a agricultura e pecuária.

Os lajedos, áreas formadas por afloramentos rochosos, mas diferente dos inselbergs, possuem altimetria próxima a depressão subsequente, constituem-se como áreas desfavorecidas para a expansão urbana da cidade.

Figura 3: Vista do centro da cidade de Pedra Branca.

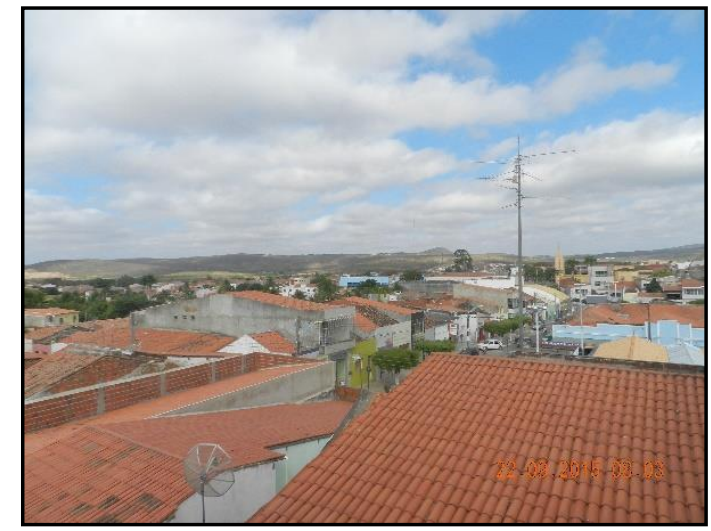

Fonte: Costa, L. R. F (2015)
Figura 4: Planície fluvial do rio Quixeramobim. Observar a ocupação de risco nas margens.

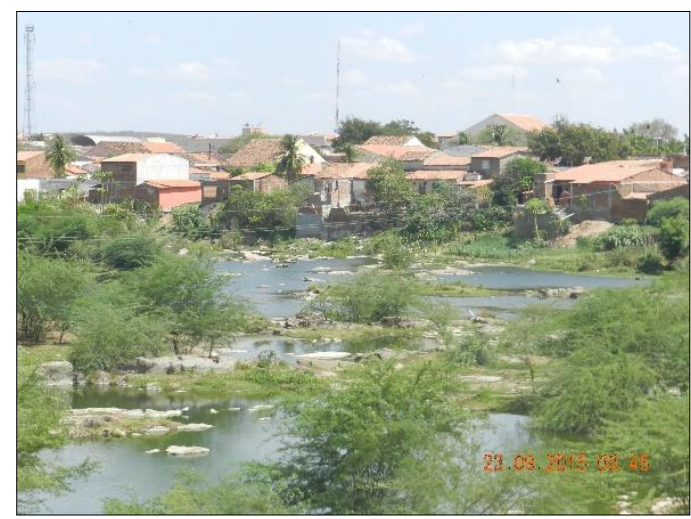

Fonte: Costa, L. R. F (2015)

\section{Considerações finais}

Ainda há necessidade de trabalhos que abordem temáticas de forma interdisciplinar, com o objetivo de visualizar problemas complexos que estão ligados a gestão e planejamento 
CONTEXTO GEOAMBIENTAL EM SÍTIO URBANO NA SUB-BACIA HIDROGRÁFICA DO RIO BANABUIÚ - CE

Luis Ricardo Fernandes da Costa; Vládia Pinto Vidal de Oliveira; Jader de Oliveira Santos

ambiental, ainda mais quando se trata de ambientes urbanos, como em pequenas e médias cidades com potencial crescimento de malha urbana.

Nesse sentido, é importante a compreensão de diversos processos que ocorrem nesses ambientes. Mesmo em áreas de pequenas e médias cidades a degradação ambiental é observada em diversas amplitudes, sendo cabíveis estudos interdisciplinares para a mitigação desses possíveis impactos.

\section{Referências}

AB'SABER, A. N. Formas de relevo: texto básico. FUNBEC: São Paulo, 1975.

AB'SABER, A. N. Geomorfologia do Sítio Urbano de São Paulo. Ed. Fac-Similar - 50 anos. São Paulo: Ed. Ateliê, 2007.

BERTALANFFY, L.V. Teoria Geral dos Sistemas. Petrópolis: Vozes, 1973.

BERTRAND, G. Paisagem e geografia física global: esboço metodológico. Caderno de ciências da terra, n.13, p- 1-27, 1971.

BOTELHO, R. G. M.; SILVA, A. S. da. Bacia Hidrográfica e Qualidade Ambiental. In: VITTE, Antônio C.; GUERRA, Antônio J. T. (orgs). Reflexões sobre a Geografia Física no Brasil. Bertrand Brasil, 2 ed. Rio de Janeiro, 2004.

CASTILHO, C. J. M.. O Ambiente Urbano numa Perspectiva Interdisciplinar:Discussão de Conceitos que Tratam das Inter-Relações Sociedade-Natureza,a partir da Geografia do Recife. Revista Brasileira de Geografia Física, v. 04, n. 05, 2011.

CEARÁ. Assembleia Legislativa. Caderno regional da sub-bacia do Banabuiú / Conselho de Altos Estudos e Assuntos Estratégicos. SANTANA, E.W. de (Coordenador). - Fortaleza: INESP, 2009.

CPRM - Serviço geológico do Brasil. Mapa geológico do Estado do Ceará. Escala 1:500.000, Ceará. CPRM, 2003.

CHIRISTOFOLETTI, A. Modelagem de Sistemas Ambientais. São Paulo: Ed. Edgard Blucher, 1999.

GUERRA, A.T.; GUERRA, A. J. T. Novo Dicionário Geológico-Geomorfológico. Rio de Janeiro: Bertrand Brasil, 1997.

IBGE. Instituto Brasileiro de Geografia e Estatística. Manual técnico de geomorfologia/IBGE, Coordenação de Recursos Naturais e Estudos Ambientais. - 2. ed. Rio de Janeiro : IBGE, 2009.

LORANDI, R; CANÇADO, C. J. Parâmetros físicos para gerenciamento de bacias hidrográficas. In: SCHIAVETTI, A; CAMARGO, A. (editores). Conceitos de Bacias Hidrográficas. Ilhéus - BA: Editora da UESC, 2005. 
CONTEXTO GEOAMBIENTAL EM SÍTIO URBANO NA SUB-BACIA HIDROGRÁFICA DO RIO BANABUIÚ - CE

Luis Ricardo Fernandes da Costa; Vládia Pinto Vidal de Oliveira; Jader de Oliveira Santos

OLIVEIRA, V.P.V. de. Zoneamento geoambiental do sertão de Quixeramobim - CE.

Coleção Mossoroense, 1990.

PIRES, J. S. R; SANTOS, J. E. Bacias Hidrográficas: integração entre o meio ambiente e desenvolvimento. Revista Ciência Hoje: Águas do Brasil: má utilização e falta de planejamento, vol. 19, nº 110. SBPC, 1995. p. 40-45.

PROJETO RADAMBRASIL. FOLHA SB.23/24 JAGUARIBE/NATAL: geologia, geomorfologia. Rio de Janeiro, 1981.

ROCHA, A. A. Sociedade e Natureza: a produção do espaço urbano em bacias hidrográficas. Edições UESB: Vitória da Conquista, 2011.

SANTOS, J. O; ROSS, J. L. S. Fragilidade ambiental urbana. Revista da ANPEGE, v. 8, n. 10, p. 127-144, 2012.

SANTOS, J.O; SOUZA, M.J.N. Abordagem geoambiental aplicada à análise da vulnerabilidade e dos riscos em ambientes urbanos. In: Boletim Goiano de Geografia. v.34. n. 2, 2014.

SOUZA, M. J. N. Geomorfologia e condições ambientais dos vales do Acaraú/Coreaú Ceará. Tese de Doutorado. Universidade de São Paulo. São Paulo, 1981.

SOUZA, M.J.N. Contribuição ao estudo das unidades morfo-estruturais do Estado do Ceará. In: Revista de Geologia. Fortaleza: v.1, p.73-91. Edições Universidade Federal do Ceará, 1988.

SOUZA, M. J. N. Bases geoambientais e esboço do zoneamento geoambiental do Estado do Ceará. In: LIMA, L. C. (Org). Compartimentação territorial e gestão regional do Ceará. Fortaleza: Funece, 2000. p. $06-103$.

SOUZA, M. J. N; OLIVEIRA, V.P.V; GRANGEIRO, M.M.G. Análise Geoambiental. In: ELIAS, D. (Org.) O novo espaço da produção globalizada - o baixo Jaguaribe. Fortaleza: Funece, 2002.

SOUZA, M. J. N; SANTOS, J.O; OLIVEIRA, V.P.V. Sistemas ambientais e capacidade de suporte na bacia hidrográfica do rio Curu-Ceará: Revista Continentes. Ano 1. n.1, 2012.

SOUZA, M. J. N; OLIVEIRA, V. P. V. Análise ambiental - uma prática da interdisciplinaridade no ensino e na pesquisa. 2011. Disponível em:

$<$ http://www.revistarede.ufc.br/revista/index.php/rede/article/viewArticle/168<. Acesso em 25 de setembro de 2013.

TEODORO, V. L. I.; TEIXEIRA, D.; COSTA, D. J. L.; FULLER, B. B. O conceito de bacia hidrográfica e a importância da caracterização morfométrica para o entendimento da dinâmica ambiental local. Revista UNIARA, v. 20, p. 227-245, 2007.

TRICART, J. Épiderme de la Terre. Paris, 1962. 
TRICART, J. Ecodinâmica. Rio de Janeiro: IBGE, 1977.

TRICART, J. Paisagem e Ecologia. Traduzido pelo Prof ${ }^{\circ}$ Carlos A. F. Monteiro, SP: Instituto de Geografia; USP, 1981. 